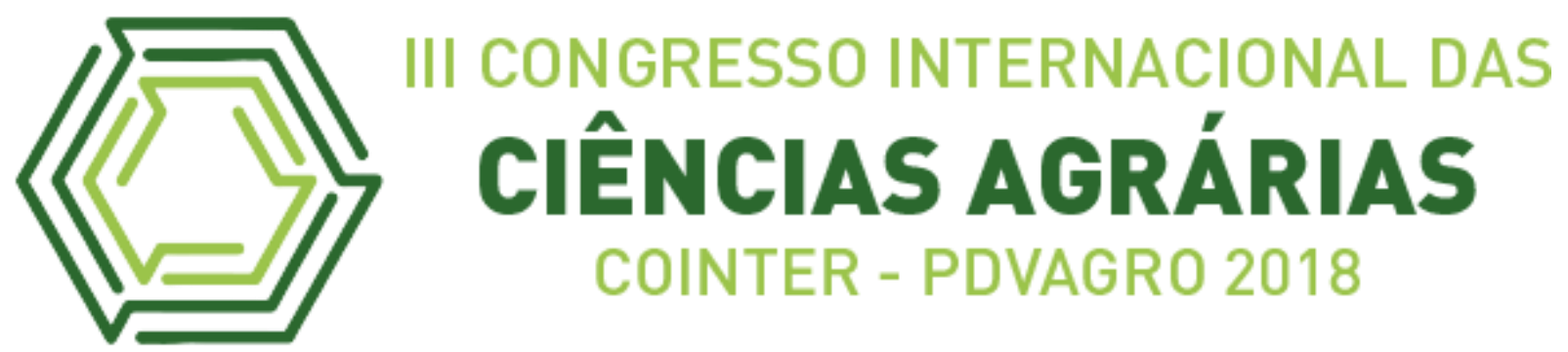

\title{
FEIRA LIVRE DA VILA DO JUABA: A NECESSIDADE DE VALORIZAÇÃO DO POVO RIBEIRINHO DO BAIXO TOCANTINS
}

\section{FREE FAIR OF THE JUABA VILLAGE: THE NEED FOR VALORIZATION OF THE PEOPLE RIBEIRINHO DO BAIXO TOCANTINS}

\author{
Apresentação: Relato de Experiência
}

Patricia Taila Trindade de Oliveira ${ }^{1}$; Iron Dhones de Jesus Silva do Carmo ${ }^{2}$; Thaynara Luany Nunes Monteiro ${ }^{3}$;Carlos Anderson Sousa de Carvalho ${ }^{4}$;Acácio Tarcísio Moreira de Melo ${ }^{5}$

\section{DOI: https://doi.org/10.31692/2526-7701.IIICOINTERPDVAGRO.2018.00736}

\section{Introdução}

A vila do Juaba é o maior distrito do município de Cametá - PA, possuindo o segundo maior colégio eleitoral do território cametaense. Sua origem é de um dos maiores Quilombos da região do Baixo Tocantins. Na região Tocantina, mais especificamente no município de Cametá, durante a segunda metade do século XVIII, foi construído o Quilombo do Mola, um dos mais importantes palcos de resistência negra no Baixo Tocantins (PINTO, 1995). Após a abolição da escravatura e com o êxodo do Quilombo do Mola surge a atual vila do Juaba, fundada no início do século XX nas margens do rio Tocantins.

Aos poucos, esta vila ribeirinha passou a ser o centro de encontro dos moradores da região na feira livre que acontece sempre aos domingos e que é um dos símbolos tradicionais e culturais da vila. A feira livre é uma das formais mais expressivas do espaço urbano da vila, pois é onde tais vivências se manifestam, por meio de trocas de experiências, de encontros, de amizades e de perpetuação e manutenção dos saberes populares, ao mesmo tempo, ela é também o lugar de trabalho, de onde se retira o sustento da família.

\footnotetext{
${ }^{1}$ Agronomia, Instituto federal do Pará campus Castanhal, patriciatailaoliveira@gmail.com

${ }^{2}$ Agronomia, Instituto federal do Pará campus Castanhal, irondhones@gmail.com

${ }^{3}$ Agronomia, Instituto federal do Pará campus Castanhal, luanynunes6@ gmail.com

${ }^{4}$ Agronomia, Instituto federal do Pará campus Castanhal, anderson_casc@hotmail.com

${ }^{5}$ Professor titular, Instituto federal do Pará campus Castanhal, acaciotmoreira@gmail.com
} 
O relato é feito com a intensão de compartilhar a experiência histórica e socioeconômica que contribuir para essa vila simples de extrema riqueza cultural. E que sofre com o esquecimento por parte do poder público. A Amazônia não é somente ambiente físico como também um ambiente humano, com uma história social, política e econômica. A comunidade internacional costuma relacionar a região somente a questão ambiental, a problemática da Amazônia não é simplesmente ecológica, mas política e social (MORÁN, 1990).

\section{Relato de Experiência}

Embora o distrito de Juaba fique próximo à sede urbana de Cametá, a estrada que dá acesso à vila está quase intrafegável, principalmente no período mais chuvoso, justamente o momento em que foi realizada a visita à feira. Além disso, é a vila mais atrasada economicamente e estruturalmente. É visível a necessidade de uma cobertura para feira que comercializava seus produtos mesmo em baixo de chuva (Figura 1).

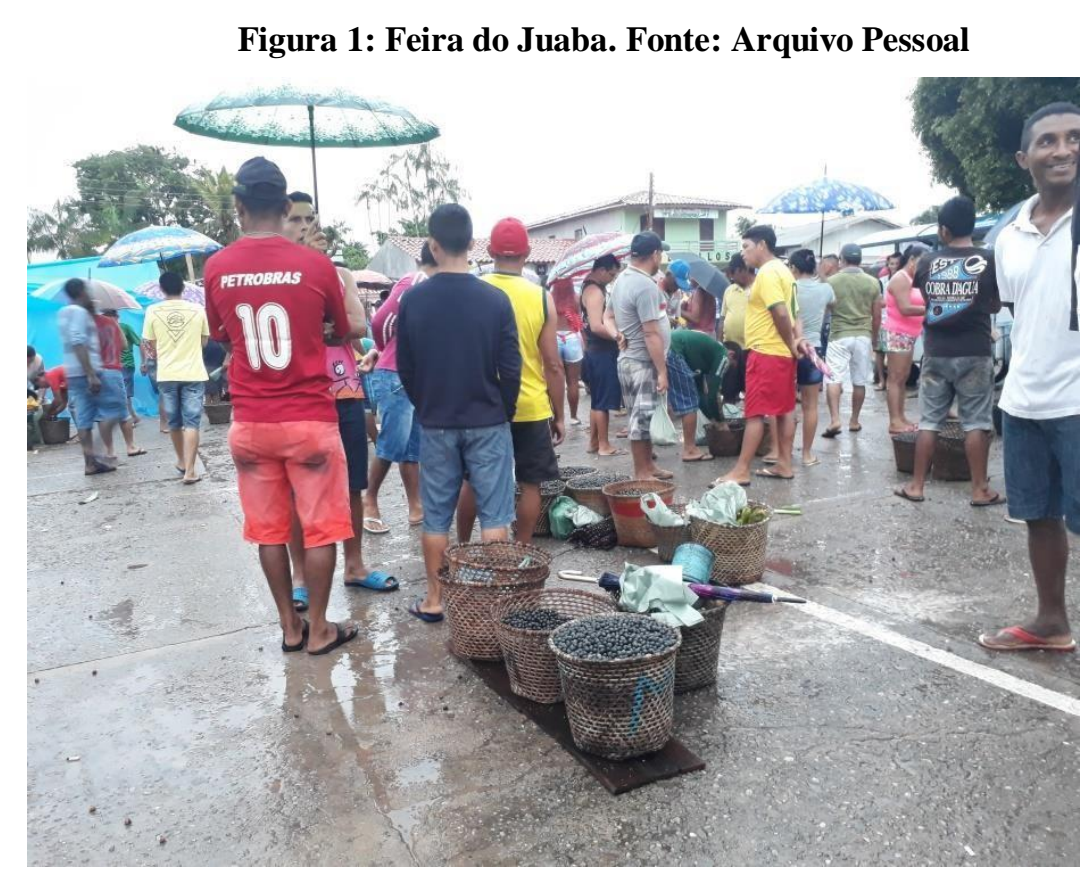

No trapiche circulam centenas de pessoas por dia, que vem diariamente na vila à procura de educação, saúde e que é utilizada principalmente pelos ribeirinhos que participam da feira para comercializar seus produtos (Figura 2). O trapiche é como um intermediário entre o rio e a vila, ele sintetiza a saída e a chegada de um conjunto de relações que envolvem mundos diversos, o da vila e o seu entorno. No entanto, o trapiche da vila esta em más condições. Foi constatada a insuficiência de infraestrutura e obras que se voltem para as demandas de natureza ribeirinha. 
Figura 2: Ribeirinho desembarcando suas mercadorias. Fonte: Arquivo Pessoal

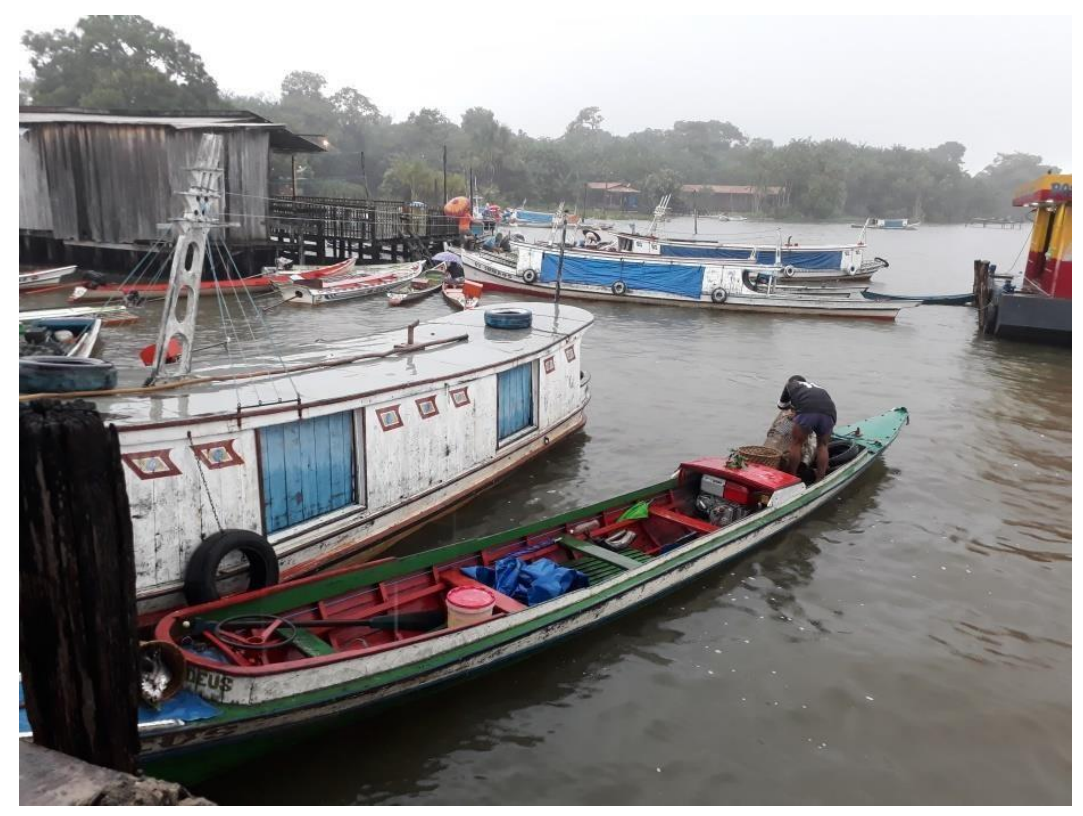

Nestes lugares de realização da vida, os diferentes grupos sociais trabalham, consomem, realizam formas culturais e vivenciam os limites do exercício da escassa cidadania (MASCARENHAS; DOLZANI, 2008). Essa mesma fração da cidade é, por excelência, espaço do valor de uso. No entanto, nem sempre essa dimensão é devidamente reconhecida. Percebe-se que o viver ribeirinho ainda carece de leituras que tornem visíveis as práticas cotidianas do sujeito para que sejam tomadas as decisão em que as experiências econômicas, lúdicas, sociais e simbólico culturais dos agentes que ali se fazem presentes sejam contempladas.

A cidade apresenta uma especificidade, que é justamente sua característica de cidade tradicional ribeirinha que se inseriu de forma diferenciada nas políticas recentes de ordenamento territorial (TRINDADE; 2008). Por conta disso, é logico que se possua politicas especificas para as necessidades da comunidade ribeirinha, fato que parece não estar sendo muito bem reconhecido pelas ações do Estado em Cametá. 


\section{Considerações}

Durante a experiência foi observado que várias das manifestações culturais da Vila de Juaba vivem à beira da extinção pela falta de uma verdadeira política pública de conservação. As universidades e organizações, na medida em que produzem conhecimento, contribuem para a busca de alternativas viabilizadoras do acesso dessas populações às políticas públicas, considerando sua realidade ecológica, fortemente marcada pelo viver ribeirinho, pelas trocas de experiência, pela familiaridade e pelas relações de amizade cultural. A feira do Juaba se caracteriza como um do símbolo na luta pacata na resistência histórica e manutenção dos povos tradicionais na região amazônica do Baixo Tocantins.

\section{Referências}

MASCARENHAS, G.; DOLZANI, M.C.S. Feira livre: territorialidade popular e cultura na metrópole contemporânea. Goiânia: Ateliê geográfico, 2008.

MORÁN, E. F. A ecologia humana das populações da Amazônia. Petrópolis Vozes, 1990.

PINTO, B.C.M. Quilombo do Mola: local de ramificação e ponto de partida para uma reconstrução Historiográfica. Recife: XVIII Simpósio Nacional de História - História e Identidade - da ANPHU, 1995.

TRINDADE JR., SC. C.; TAVARES, M. G. C., E. "Cametá: análise de uma paisagem amazônica". In: (Orgs.). Cidades ribeirinhas na Amazônia: mudanças e permanências. Belém: Edufpa, 2008. 